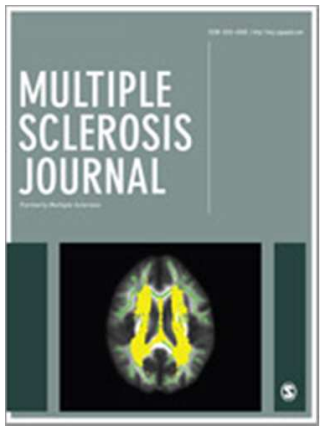

\title{
The effect of oral immunomodulatory therapy on treatment uptake and persistence in multiple sclerosis
}

\begin{tabular}{|c|c|}
\hline Journal: & Multiple Sclerosis Journal \\
\hline Manuscript ID: & MSJ-14-0901.R1 \\
\hline Manuscript Type: & Original Research Paper \\
\hline Date Submitted by the Author: & $\mathrm{n} / \mathrm{a}$ \\
\hline Complete List of Authors: & $\begin{array}{l}\text { Warrender-Sparkes, Matthew; University of Melbourne, Department of } \\
\text { Medicine } \\
\text { Spelman, Tim; University o Melbourne, Department of Medicine; Royal } \\
\text { Melbourne Hospital, Department of Neurology } \\
\text { Izquierdo, Guillermo; Hospital Universitario, Neurology } \\
\text { Trojano, Maria; University of Bari, Department of Basic Medical Sciences, } \\
\text { Neuroscience and Sense Organs } \\
\text { Lugaresi, Alessandra; University G. D'Annunzio, Dept. of Neuroscience and } \\
\text { Imaging } \\
\text { Grand'Maison, Francois; Charles LeMoyne Hospital, Neurology } \\
\text { Havrdova, Eva; Charles University in Prague, Neurology } \\
\text { Horakova, Dana; Charles University in Prague, Neurology } \\
\text { Boz, Cavit; Karadeniz Technical University, Neurology } \\
\text { Oreja-Guevara, Celia; Health Research Institute (IdiPAZ), University } \\
\text { Hospital La Paz/Autónoma University of Madrid, Neurology, } \\
\text { Neuroimmunology and Multiple Sclerosis Unit, } \\
\text { Alroughani, Raed; Amiri Hospital, Medicine - Neurology } \\
\text { Iuliano, Gerardo; A.O. Ospedali Riuniti di Salerno, Neurology } \\
\text { Duquette, Pierre; Charles LeMoyne Hospital, Neurology } \\
\text { Girard, Marc; Charles LeMoyne Hospital, Neurology } \\
\text { Terzi, Murat; Ondokuz Mayis University, Medical School, Neurology } \\
\text { Hupperts, Raymond; Orbis Medical Center, Orbis Medical Center } \\
\text { Grammond, Pierre; Hotel Dieu De Levis, Neurology } \\
\text { Petersen, Thor; Aarhus University Hospital, Department of Neurology } \\
\text { Fernández-Bolaños, Ricardo; Hospital Universitario Virgen de Valme, } \\
\text { Neurology } \\
\text { Fiol, Marcela; Raul Carrea Institute for Neurological Reserach (FELNI), } \\
\text { Neurology } \\
\text { Pucci, Eugenio; Hospital of Macerata, Neurology Department } \\
\text { Lechner-Scott, Jeannette; John Hunter Hospital, Neurology } \\
\text { Verheul, Freek; Groene Hart Ziekenhuis, Neurology }\end{array}$ \\
\hline
\end{tabular}


Cristiano, Edgardo; hospital italiano, neurology

Vanpesch, Vincent; Cliniques Universitaires, Neurology

Petkovska-Boskova, Tatjana; Clinic of Neurology Clinical Center, Neurology

Moore, Fraser; Mcgill University, Neurology

Kister, Ilya; New York University Langone Medical Center, Neurology

Bergamaschi, Roberto; Neurological Institute Mondino, Multiple sclerosis

Centre - Clinical Neurology

Saladino, María Laura; INEBA, Neurology

Slee, Mark; Flinders Medical Centre, Department of Neurology

Barnett, Michael; The University of Sydney, Medicine

Amato, Maria Pia; University of Florence, Neurology

Shaw, Cameron; Geelong Hospital, Department of Neurology

Shuey, Neil; St Vincent's Hospital, Department of Neurology

Young, Carolyn; Walton Centre for Neurology and Neurosurgery, Neurology Gray, Orla; Royal Victoria Hospital, Neurology

Kappos, Ludwig; University of Basel and University Hospital, Department of Neurology

Butzkueven, Helmut; University o Melbourne, Department of Medicine;

Royal Melbourne Hospital, Department of Neurology; Box Hill Hospital,

Department of Neurology

Kalincik, Tomas; University o Melbourne, Department of Medicine; Royal

Melbourne Hospital, Department of Neurology

Jokubaitis, Vilija; University of Melbourne, Department of Medicine

Keywords: Relapsing/remitting, Disease modifying therapies, Multiple sclerosis

Objective

To analyse the effect of the introduction of fingolimod, the first oral disease modifying therapy, on treatment utilisation and persistence in an

international cohort of patients with multiple sclerosis.

\section{Methods}

MSBASIS, a prospective, observational sub-study of the MSBase registry, collects demographic, clinical and paraclinical data on patients followed from MS onset $(n=4718)$. We conducted a multivariable conditional risk set survival analysis to identify predictors of treatment discontinuation and assess if the introduction of fingolimod has altered treatment persistence.

\section{Results}

Abstract:

A total of 2640 patients commenced immunomodulatory therapy. Following the introduction of fingolimod, patients were more likely to discontinue all other treatments (hazard ratio $1.64, \mathrm{p}<0.001$ ) while more patients switched to fingolimod than any other therapy ( $42.3 \%$ of switches). Patients switched to fingolimod due to convenience. Patients treated with fingolimod were less likely to discontinue treatment compared to other therapies $(p<0.001)$. Female sex, country of residence, younger age, a high EDSS and relapse activity were all independently associated with higher rates of treatment discontinuation.

\section{Conclusion}

Following the availability of fingolimod, patients were more likely to discontinue injectable treatments. Those who switched to fingolimod were more likely to do so for convenience. Persistence was improved on fingolimod compared to other medications. 


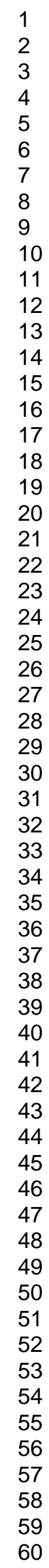




\section{TITLE PAGE}

\section{Title}

The effect of oral immunomodulatory therapy on treatment uptake and persistence in multiple sclerosis

\section{Authors and affiliations}

Matthew Warrender-Sparkes; Department of Medicine, University of Melbourne, Melbourne, Australia

Tim Spelman; Department of Neurology, Royal Melbourne Hospital, Melbourne, Australia

Guillermo Izquierdo; Hospital Universitario Virgen Macarena, Sevilla, Spain Maria Trojano; Department of Basic Medical Sciences, Neuroscience and Sense Organs, University of Bari, Italy

Alessandra Lugaresi; MS Center, Department of Neuroscience, Imaging and Clinical Sciences, University 'G. d'Annunzio', Chieti, Italy

Francois Grand'Maison; Neuro Rive-Sud, Hôpital Charles LeMoyne, Quebec, Canada

Eva Havrdova; Department of Neurology and Center of Clinical Neuroscience, 1st Faculty of Medicine, General University Hospital and Charles University in Prague, Czech Republic

Dana Horakova; Department of Neurology and Center of Clinical Neuroscience, 1st Faculty of Medicine, General University Hospital and Charles University in Prague, Czech Republic

Cavit Boz; Karadeniz Technical University, Trabzon, Turkey

Celia Oreja-Guevara; University Hospital San Carlos, IdISSC, Madrid, Spain

Raed Alroughani; Amiri Hospital, Kuwait City, Kuwait

Gerardo Iuliano; Ospedali Riuniti di Salerno, Salerno, Italy

Pierre Duquette; Hôpital Notre Dame, Montreal, Canada

Marc Girard; Hôpital Notre Dame, Montreal, Canada

Murat Terzi; Ondokuz Mayis Üniversitesi, Samsun, Turkey

Raymond Hupperts; Orbis Medicle Center, Sittard, The Netherlands

Pierre Grammond; Hotel-Dieu de Levis, Quebec, Canada 
Thor Petersen; Aarhus University Hospital, Aarhus C, Denmark

Ricardo Fernandez-Bolanos; Hospital Universitario Virgen de Valme, Seville, Spain

Marcela Fiol; FLENI, Buenos Aires, Argentina

Eugenio Pucci; Ospedale di Macerata, Macerata, Italy

Jeannette Lechner-Scott; John Hunter Hospital, Newcastle, Australia

Freek Verheul; Groen Hart Ziekenhuis, Gouda, The Netherlands

Edgardo Cristiano; Hospital Italiano, Buenos Aires, Argentina

Vincent Van Pesch; Cliniques Universitaires Saint-Luc, Brussels, Belgium

Tatjana Petkovska-Boskova; Neurology Clinical Center, Skopje, Macedonia

Fraser Moore; Jewish General Hospital, Montreal, Canada

Ilya Kister; New York University Langone Medical Center, New York, USA

Roberto Bergamaschi; National Neurological Institute C. Mondino, Pavia, Italy

Maria Laura Saladino; INEBA, Buenos Aires, Argentina

Mark Slee; Flinders University and Medical Centre, Adelaide, Australia

Michael Barnett; Brain and Mind Research Institute, Sydney, Australia

Maria Pia Amato; Department NEUROFARBA, Section of Neurosciences, University of Florence, Florence, Italy

Cameron Shaw, Geelong Hospital, Geelong, Australia

Neil Shuey, St Vincent's Hospital, Melbourne, Australia

Carolyn Young; The Walton Centre for Neurology and Neurosurgery, Liverpool, United Kingdom

Orla Gray; Craigavon Area Hospital, Portadown, United Kingdom

Ludwig Kappos; University Hospital Basel, Neurology, Departments of Medicine, Clinical Research and Biomedicine, Basel, Switzerland Helmut Butzkueven; Department of Medicine, University of Melbourne, Melbourne, Australia, Department of Neurology, Royal Melbourne Hospital, Melbourne, Australia, and Department of Neurology, Box Hill Hospital, Monash University, Box Hill, Australia

Tomas Kalincik t; Department of Medicine, University of Melbourne, Melbourne, Australia, and Department of Neurology, Royal Melbourne Hospital, Melbourne, Australia 
Vilija Jokubaitis t; Department of Medicine, University of Melbourne, Melbourne, Australia

on behalf of the MSBase study group*

*Contributing members of the MSBase Study Group are listed in the Acknowledgements.

tThese authors contributed equally to the manuscript.

\section{keywords}

multiple sclerosis, disease modifying therapy, fingolimod, medication persistence, MSBase

\section{Corresponding author}

Tomas Kalincik; L4 Centre, Melbourne Brain Centre at Royal Melbourne Hospital, Grattan St, Parkville VIC 3050, Australia; Tel: +61 39342 4404, Fax: +61 393495997 


\begin{abstract}
Objective

To analyse the effect of the introduction of fingolimod, the first oral disease modifying therapy, on treatment utilisation and persistence in an international cohort of patients with multiple sclerosis.
\end{abstract}

\title{
Methods
}

MSBASIS, a prospective, observational sub-study of the MSBase registry, collects demographic, clinical and paraclinical data on patients followed from MS onset $(n=4718)$. We conducted a multivariable conditional risk set survival analysis to identify predictors of treatment discontinuation and assess if the introduction of fingolimod has altered treatment persistence.

\section{Results}

A total of 2640 patients commenced immunomodulatory therapy. Following the introduction of fingolimod, patients were more likely to discontinue all other treatments (hazard ratio 1.64, $p<0.001)$ while more patients switched to fingolimod than any other therapy $(42.3 \%$ of switches). Patients switched to fingolimod due to convenience. Patients treated with fingolimod were less likely to discontinue treatment compared to other therapies $(p<0.001)$. Female sex, country of residence, younger age, a high EDSS and relapse activity were all independently associated with higher rates of treatment discontinuation.

\section{Conclusion}

Following the availability of fingolimod, patients were more likely to discontinue injectable treatments. Those who switched to fingolimod were more likely to do so for convenience. Persistence was improved on fingolimod compared to other medications. 


\section{Introduction}

Disease modifying therapies (DMT) are moderately effective at reducing relapse rates, slowing disability progression, decreasing brain lesion accumulation and delaying conversion of clinically isolated syndrome (CIS) to relapsing-remitting multiple sclerosis (RRMS). ${ }^{1,2}$ Patients who persist on therapy have been reported to undergo fewer hospital admissions and to incur lower MS related healthcare costs when compared to patients who discontinue or never initiate a DMT. ${ }^{3}$

Until recently, the injectable compounds IFN $\beta-1$ a IM, IFN $\beta-1$ a SC, IFN $\beta-1 b$ and glatiramer acetate were the only DMTs available. Despite evidence from controlled studies supporting their efficacy, the uptake of, and persistence on, these therapies has been limited by their parenteral route of administration, side effects and a perceived lack of efficacy on the part of the patient brought about by the unpredictable, intermittent nature of relapses. ${ }^{4,5}$ Studies have shown that persistence on injectable DMTs is surprisingly short. It has been reported that between $4 \%$ and $57 \%$ of patients discontinue treatment within 12 months of DMT initiation, with average persistence on therapy ranging from approximately 0.6 to 2.8 years and significant differences existing across countries and between nationalities. ${ }^{5-11}$

Fingolimod, the first widely available orally administered DMT, has been shown to be superior to both placebo and IFN $\beta-1$ a IM in reducing relapse activity and brain lesion accumulation. ${ }^{12-14}$ Given it lacks some of the tolerability issues inherent in the injectable therapies, the introduction of fingolimod brings with it the prospect of improved treatment tolerance, increased treatment persistence and, potentially, improved patient outcomes. However, no large prospective studies have assessed patterns of treatment utilisation and switching since the introduction of fingolimod. The few published studies that have are retrospective in nature, with limited follow-up. ${ }^{15,16}$

This study aims to characterise how the introduction of fingolimod has affected treatment persistence, treatment utilisation and predictors of treatment discontinuation in an international, prospective, observational cohort of patients with CIS and early RRMS. 


\section{Methods}

\section{Ethics Statement}

The MSBase registry $^{17}$ (registered with WHO ICTRP, ID ACTRN12605000455662) was approved by the Melbourne Health Human Research Ethics Committee. Human Research Ethics Committee approval, or exemptions according to local regulations, as well as written informed consent from patients to participate in the MSBase Registry, was obtained at each participating site.

\section{Database}

The MSBase Incident Study (MSBASIS) is an international, observational cohort study of patients seen from CIS onset, from 69 treatment centres across 19 countries (see Supplementary Table 1). The study commenced in December 2004. Data extraction took place on the $20^{\text {th }}$ of January 2015. MSBASIS requires a minimum baseline dataset of MS related outcomes to be recorded at first visit, as well as a minimum dataset to be provided at each follow-up visit, which must occur at least annually. Patient datasets were recorded in near realtime using the iMed electronic patient record system.

\section{Patients and Procedures}

A patient was considered eligible for the study if a participating neurologist confirmed the diagnosis of CIS within 12 months of CIS onset using the 2005 or 2010 McDonald diagnostic criteria as per the year of diagnosis. Patients were excluded from the study if they had a diagnosis of primary progressive MS, were prescribed fingolimod as part of a clinical trial or were prescribed mitoxantrone or an oral DMT other than fingolimod (the latter exclusion being due to insufficient commencements per therapy for statistical analysis). The minimum baseline dataset included date of CIS onset, clinical presentation, Kurtzke Expanded Disability Status Scale (EDSS) and Functional System scores, and a cerebral magnetic resonance imaging 
(MRI) scan available within 12 months of CIS onset. The minimum dataset collected at each follow-up appointment included date of visit, date of onset and duration of any relapses, DMT commencement and cessation dates, glucocorticoid therapy for relapses and EDSS scores including functional system scores. Reasons for treatment discontinuation were recorded for a proportion of treatment cessations. Online EDSS competency certification was required at each participating centre. The quality assurance procedures are described elsewhere. ${ }^{4}$ For the purpose of this analysis, the start of the post-oral treatment epoch was determined for each country as the date of the first fingolimod initiation outside a clinical trial in patients within MSBASIS. Duration of each treatment within either of these epochs was specified, with leftand right-side censoring introduced to categorise the treatment extending across both epochs. $^{18}$

\section{Definitions}

A relapse was defined as occurrence of new symptoms or exacerbation of existing symptoms persisting for $>24$ hours, in the absence of concurrent illness or fever, and occurring at least 30 days after a previous relapse. Baseline annualised relapse rate (ARR) was calculated as the number of relapses experienced prior to treatment divided by the years between CIS onset and treatment commencement. The number of relapses in the 6 months preceding treatment discontinuation or censoring was noted. Change in EDSS was defined as the difference in EDSS scores between the earliest and latest visits within the treatment period. Treatment cessation was defined as a period of 90 or more days without treatment after a DMT was initiated. Treatment switch was defined as any DMT commencement following a previously discontinued therapy. A delayed continuation was defined as stopping a DMT for more than 90 days only to reinitiate the same DMT. 


\section{Statistical Analysis}

In order to analyse treatment duration, patient data were censored at the most recent visit date. Treatment persistence for all initiation events was visualised using the Kaplan-Meier method. The formal statistical evaluation of the effect of treatment epoch and other predictors of treatment persistence was conducted with a two-step conditional risk set model, with the final multivariable model built based on the outcomes of a series of univariable models. ${ }^{19} \mathrm{~A}$ variation of the Andersen-Gill model (a proportional hazards model with robust variance estimation), the conditional risk set model allows for multiple events and adjusts for the event dependence (such as the individual propensity to treatment discontinuations). Hazard proportionality was assessed in both the univariable and multivariable models by analysis of scaled Schoenfeld residuals. Interactions between epoch and all other variables were tested to determine whether the introduction of fingolimod had altered predictors of treatment discontinuation. Fisher's exact test was used to test for differences in the recorded reasons for treatment discontinuation between DMTs. All reported $p$-values are two-tailed and $p<0.05$ was considered significant for each analysis. All analyses were performed using Stata version 12.0 (StataCorp, College Station, Texas).

\section{Results}

\section{Patient Demographics and Treatment Characteristics}

A total of 4111 patients were included in the study, Figure 1 summarises patient disposition in relation to treatment epoch and exclusion criteria. Of these, a total of 2640 patients were prescribed at least one DMT over a median follow-up period of 4.8 years (Interquartile range (IQR): $2.4,7.1$ ), with $71.4 \%$ of first treatment commencements occurring prior to the introduction of oral therapies and $28.6 \%$ occurring after fingolimod became available. Baseline characteristics for patients at first treatment commencement for each DMT are summarised in Table 1. Patients initiating therapy with natalizumab appeared younger at symptom onset and treatment start, had higher relapse and MRI activity and were less likely to start therapy during 
CIS when compared to patients on other treatments. Conversely, patients were more likely to start therapy during $\mathrm{CIS}$ with IFN $\beta-1 \mathrm{a}$ IM.

We recorded 1617 subsequent treatment commencements by 1102 patients, comprising 1399 treatment switches and 218 delayed continuations, resulting in 4257 total treatment starts over 12878 patient years of follow-up. Of these, 1204 treatments $(28.3 \%)$ occurred exclusively in the pre-oral epoch, 1781 (41.8\%) occurred exclusively in the post-oral epoch and 1272 treatments $(29.9 \%)$ crossed over between the two epochs.

----Figure 1-----

----Table 1----

\section{Treatment Persistence}

One year after treatment commencement, $19.7 \%$ of all treatments had been discontinued.

When analysing each DMT individually at one year after commencement, $22.6 \%$ of glatiramer acetate treatments, $18.9 \%$ of IFN $\beta-1 \mathrm{a}$ IM treatments, $21.0 \%$ of IFN $\beta-1 \mathrm{~b}$ treatments, $19.7 \%$ of IFN $\beta-1$ a SC treatments, $21.2 \%$ of natalizumab treatments and $10.5 \%$ of fingolimod treatments had been discontinued. Table 2 summarises the treatment discontinuation events by sex, location, DMT identity, EDSS at treatment start and baseline MRI results.

\section{Predictors of Treatment Discontinuation}

Univariable analyses revealed that sex, location, treatment identity, pre-/post-oral epoch, age at treatment start, relapse activity and EDSS step at treatment start were all associated with changes in treatment discontinuation rates and were therefore included in the multivariable model. The multivariable analysis revealed that patients were significantly more likely to discontinue treatment in the post-oral epoch (figure 2a) (hazard ratio $(H R): 1.64 p<0.001$ ). However, while patients had an overall greater risk of discontinuing therapy in the post-oral 
epoch, those patients who commenced fingolimod had a significantly lower risk of treatment discontinuation when compared to patients on all other therapies (figure 2b) (HR: 0.46, $p<0.001$ when compared to IFN $\beta-1$ a SC).

The multivariable model also demonstrated that male sex was predictive of a decreased risk of treatment discontinuation (Figure 2c), as was older age at treatment start. An EDSS of greater than 4 at treatment start when compared to an EDSS score of zero was associated with a greater risk of treatment discontinuation. Patients who discontinued therapy were more likely to have experienced relapses within the six months preceding treatment discontinuation, while patients being treated in all locations except for the Netherlands and Canada had a lower risk of treatment discontinuation when compared to patients in Australia. Table 2 provides detailed results of univariable and multivariable analyses. None of the tested interactions between epoch and other variables reached statistical significance.

----Figure 2----

----Table 2----

\section{Treatment Switches}

Before the introduction of oral therapies, the cohort recorded 2476 treatment commencements, including 519 treatment switches. The majority of patients switched to glatiramer acetate (28.5\%), IFNß-1a SC (26.2\%) or natalizumab (26.4\%). In the post-oral epoch, a total of 3053 treatments, including 882 switches, took place. Switching behaviour changed dramatically in the post-oral epoch, with the majority of switches being to fingolimod (42.3\%), while $15.8 \%$ of switches were to glatiramer acetate, $13.0 \%$ were to IFNß-1a SC and $21.1 \%$ were to natalizumab. Patient switching behaviours before and after the introduction of fingolimod are summarised in Table 3 and Table 4, respectively. 
----Table 3----

----Table 4----

\section{Reasons for Treatment Discontinuation and Switching}

Recording of categorically described reasons for treatment discontinuation is not a mandatory part of the MSBASIS observational protocol, but the data was available for $54.8 \%$ of discontinuations. Table 5 reports the reasons for treatment discontinuation across all therapies, showing that an adverse event or lack of tolerance was the most common reason for treatment discontinuation amongst patients on IFN $\beta-1 \mathrm{a} S \mathrm{~S}, \mathrm{IFN} \beta-1 \mathrm{~b}$ and glatiramer acetate (31.0 - 36.0\% of recorded discontinuations) while patients on IFN $\beta-1$ a appeared more likely to discontinue treatment due to a lack of improvement (30.2\%). Patients on fingolimod most commonly discontinued therapy due to either a lack of tolerance or lack of improvement ( $26.4 \%$ and $28.3 \%$ respectively). Patients on natalizumab most commonly discontinued due to a scheduled stop (45.0\%), a category that was often used in association with positive John Cunningham virus serology.

When examining the reasons recorded for switching treatments after the introduction of oral therapies (see Table 6), a relatively larger proportion of patients switching to fingolimod did so for convenience $(10.7 \%)$ compared to patients switching to natalizumab $(2.6 \%)$ or other injectables (6.4\%). Patients who stopped their previous therapy due to a lack of improvement, persistence of relapses or progression of disease made up the largest proportion of patients who subsequently commenced natalizumab. Patients were relatively less likely to switch to natalizumab after stopping their previous therapy due to an adverse event or lack of tolerance and a comparatively small proportion of patients switching to oral therapies switched after pregnancy compared to patients switching to natalizumab or to other injectables. 
----Table 6----

\section{Discussion}

In this analysis of prospectively collected data from the MSBase registry seen-from-onset cohort, we have shown that patients were more likely to discontinue immunomodulatory therapy once fingolimod became available, while their treatment persistence improved if treated with fingolimod compared to all other DMTs.

We found that $10.5 \%$ of patients prescribed fingolimod and between $18.9 \%$ and $22.6 \%$ of patients prescribed injectable DMTs discontinued treatment within 12 months of initiation. These results are in keeping with discontinuation rates of injectable DMTs reported by other studies. Retrospective American studies have reported 12-month discontinuation rates between $26 \%$ and $57 \% .{ }^{8} 9$ Prospective European studies investigating long term adherence to injectable therapies have reported discontinuation rates between $4 \%$ over 12 months and $46 \%$ over 4.2 years. $^{10,11}$ Given that the MSBase registry is composed of patients from treatment centres across a range of countries around the world, it is important to note that indications for fingolimod prescription differ between countries. While fingolimod is available as a first line therapy in countries such as Australia, the United States, Switzerland and Kuwait, in all other European Union member countries, including Italy and Spain, fingolimod, similar to natalizumab, is prescribed primarily as a second line therapy, with first line indication only for patients with very active disease. Prior MSBase studies, which investigated treatment persistence on two dosages of IFN $\beta-1$ a SC reported annualised discontinuation rates of $25 \%$ and $20 \%$ for the lower and higher doses, respectively. ${ }^{4}$ While another study, which used the MSBASIS cohort to examine first treatment persistence, found that between $31 \%$ and $44 \%$ of patients discontinued injectable therapy over a median follow-up period between 2.3 years and 3.0 years. ${ }^{20}$ To date, the only available study investigating adherence to fingolimod in a real world setting was published by Agashivala and colleagues. This study used a retrospective 
pharmaceutical claims dataset with 12 months of follow-up. Among patients living in the United States with previous DMT experience, $26 \%$ of those prescribed fingolimod and between $37 \%$ and $57 \%$ of those prescribed injectable DMTs had discontinued therapy over 12 months of follow-up. These results are in agreement with our observation that patients on fingolimod discontinue treatment at a slower rate than patients on injectable DMTs. ${ }^{15}$

We have shown that an adverse event or lack of tolerability was the most common reason provided for treatment discontinuation across most of the injectable therapies, the exception being IFN $\beta-1$ a IM for which a lack of improvement was the most common reason provided. This finding is consistent with other studies. ${ }^{5,21,22}$ Agashivala et al. suggested that the better persistence on fingolimod may be attributed to the once daily oral administration and lack of side effects frequently encountered with injectable DMTs, such as influenza-like symptoms and injection site reactions. ${ }^{15}$ In our study, the proportion of patients who reported lack of tolerance/adverse event as a reason for fingolimod discontinuation was in the range of that for the injectable DMTs. Here we report that a significantly higher proportion of patients switched to fingolimod, and perhaps persisted on treatment, for convenience $(10.7 \%)$ when compared to patients switching to injectable therapies or natalizumab. However, this result is limited by the small number of patients who discontinued fingolimod over the follow-up period (71 patients, of whom 53 provided reasons for discontinuation). The most common reason for switching to fingolimod was a lack of improvement on a previous therapy. Given that fingolimod has a second line indication in a majority of the countries included in this study, this result is not unexpected.

Our study demonstrated that the introduction of fingolimod has changed treatment switching patterns. In the pre-oral epoch, $73.6 \%$ of patients who switched therapies switched to one of the injectable DMTs, while $26.4 \%$ of switching patients escalated therapy to natalizumab. These results are consistent with retrospective studies that have looked at treatment switching patterns in MS prior to fingolimod introduction, which found that around $25 \%$ of patients on injectable therapies escalated to natalizumab. ${ }^{16,23}$ Treatment switching behaviour was altered 
considerably in the post-oral epoch, with switching to fingolimod largely replacing the switching between IFN/GA preparations from the pre-oral epoch. Once it became available, $42.3 \%$ of switching patients switched to fingolimod, accounting for almost $90 \%$ of all fingolimod treatment initiations in our cohort. This reduced the proportion of patients switching to other injectables or natalizumab to $36.6 \%$ and $21.1 \%$, respectively when compared to their pre-oral epoch share. The relatively smaller decrease in the proportion of patients switching to natalizumab may reflect its higher efficacy, which predisposes it for use in active disease. ${ }^{24-26}$ We have supported this notion by showing that a relatively higher proportion of patients escalated therapy to natalizumab due to ongoing disease activity despite treatment (73.0\%). Female sex, Australian residence, younger age at treatment start, a high EDSS at treatment commencement and on-treatment relapse activity were additional, independent, predictors of a shorter time to treatment discontinuation. Our finding that country of residence is closely related to treatment persistence, and that females are at a higher risk of discontinuing treatment, replicates and extends prior MSBasis cohort study results. ${ }^{20}$ The propensity for females to discontinue therapy at a greater rate than males may be related to childbearing, with a planned or confirmed pregnancy accounting for between $8.5 \%$ and $13.4 \%$ of all recorded reasons for treatment discontinuation among female patients. This highlights a need for appropriate support and counselling of women planning pregnancy to ensure that they reengage with treatment as soon as practicable post-pregnancy to guard against disability worsening. ${ }^{27}$ We further confirmed the findings of prior studies showing that a high EDSS at treatment commencement is associated with treatment discontinuation. ${ }^{5,8}$ However, here we found that relapse rate on treatment, rather than increasing EDSS on treatment is associated with a significantly increased risk of treatment discontinuation The prospective, observational nature of this study allowed us to follow a well-defined patient cohort representative of clinical practice at tertiary MS centres, over an extended period of follow-up. However, it is important to acknowledge that our data was incomplete in some areas, with a relative lack of MRI data and non-mandatory reporting of reasons for 
discontinuation. There was also a discrepancy in the proportion of reasons for discontinuation recorded for patients on fingolimod (74.6\%) as compared to injectables (52.8\%), which could potentially bias our results. Similarly, data on comorbid conditions, which have been shown to affect treatment adherence ${ }^{28}$ is not collected as a mandatory part of the MSBASIS dataset and thus any potential effect could not be assessed. While our analysis had sufficient power to assess our primary endpoint, analysis of the interaction between epoch and other variables may have been underpowered. The observed variability in the length of follow up between treatment groups is due to their differing periods of availability, similarly, the observed variability in follow up between countries is due to the differing periods of involvement of the various treatment centres within the MSBASIS study (eTable 1).

In this study, we have shown that patients with early multiple sclerosis, treated at tertiary MS centres, are more likely to discontinue non-oral therapy in the post-oral epoch, while patients who switch to or initiate fingolimod tend to persist on therapy longer in comparison to patients on injectable DMTs. We speculate that this increased discontinuation rate may be driven by a large proportion of patients finding injectable treatment regimens relatively onerous and subsequently switching to oral DMTs due to their perceived improved tolerability and more convenient route of administration. In this study, we assessed how treatment behaviours have changed with the introduction of the first oral DMT. However further analyses are required to determine whether persistence on fingolimod is superior to that of other oral DMTs once they become more widely available and prescribed. While it is encouraging to see improved treatment persistence in patients taking fingolimod, it remains to be shown if this improved persistence will be associated with improvements in patient outcomes such as disability progression, relapse rate and MRI activity. 


\begin{abstract}
Acknowledgements
MSBase study group contributors: From the MS-Centrum Nijmegen, Nijmegen, The Netherlands Dr Cees Zwanikken; from the Centre Hospitalier del'Universite de Montreal, Hôpital Notre-Dame, Canada, Dr Elaine Roger and Dr Pierre Despault; from New York University Langone Medical Center, USA, Dr llya Kister; from the Royal Melbourne Hospital, Australia, Dr Mark Marriott, Dr Anneke Van der Walt, Dr John King, Dr Jill Byron, Ms Lisa Morgan and Ms Eloise Hansen; from Box Hill Hospital, Monash University, Australia, Dr Olga Skibina and Ms Jodi Haartsen; from John Hunter Hospital, Australia, Dr David Williams and Dr Lisa Dark; from Department of Neuroscience, Imaging and Clinical Sciences, University 'G. d'Annunzio', Italy, Dr Giovanna De Luca, Dr Valeria Di Tommaso, Dr Daniela Travaglini, Ms Erika Pietrolongo, Dr Maria di loia, Dr Deborah Farina and Dr Luca Mancinelli; from Hopital Tenon, Paris, France, Dr Etienne Roullet; from FLENI, Argentina, Dr Jorge Correale and Dr Celica Ysrraelit; From INEBA, Argentina, Dr Fernando Caceres; from Ospedale di Macerata, Italy, Dr Elisabetta Cartechini and Dr Giorgio Giuliani; from Hospital Italiano, Argentina, Dr Juan Ignacio Rojas and Dr Liliana Patrucco; from St Vincent's Hospital, Australia, Dr Mark Paine; from Craigavon Area Hospital, United Kingdom, Dr Stella Hughes; from Rodanotech, Geneva, Switzerland, Mr Samir Mechati, Mr Matthieu Corageoud, Mr Alexandre Bulla.
\end{abstract}

Funding acknowledgement: The work was supported by the NHMRC Early Career Fellowship [1071124], Multiple Sclerosis Research Australia Postdoctoral Fellowship [11-054], NHMRC Career Development Award [628856], NHMRC Project Grant [1032484], NHMRC Centre for Research Excellence [1001216] and the MSBase Foundation. The MSBase Foundation is a not-for-profit organization that receives support from Merck Serono, Biogen Idec, Novartis Pharma, Bayer-Schering, Sanofi-Aventis and BioCSL.

\title{
Conflict of Interest Statement
}

Alessandra Lugaresi is a Bayer Schering, Biogen Idec, Genzyme, Merck Serono Advisory Board Member. She received travel grants and honoraria from Bayer Schering, Biogen Idec, Merck Serono, Novartis, Sanofi/Genzyme and Teva, research grants from Bayer Schering, Biogen Idec, Merck Serono, Novartis, Sanofi and Teva, travel and research grants from the Associazione Italiana Sclerosi Multipla.

Cavit Boz has received travel grants from Merck Serono, Biogen Idec, Novartis, BayerSchering, Merck-Serono and Teva; has participated in clinical trials by Sanofi Aventis, Roche and Novartis.

Celia Oreja-Guevara received honoraria as consultant on scientific advisory boards from Biogen-Idec, Bayer-Schering, Merck-Serono, Teva and Novartis; has participated in clinical trials/other research projects by Biogen-Idec, GSK, Teva and Novartis.

Francois Grand'Maison received honoraria from Biogen Idec, Genzyme, Novartis and Roche. Gerardo luliano had travel/accommodations/meeting expenses funded by Bayer Schering, Biogen Idec, Merck Serono, Novartis, Sanofi Aventis, and Teva Guillermo Izquierdo received speaking honoraria from Biogen-Idec, Novartis, Sanofi, Serono and Teva.

Helmut Butzkueven has served on scientific advisory boards for Biogen Idec, Novartis and Sanofi-Aventis and has received conference travel support from Novartis, Biogen Idec and Sanofi Aventis. He serves on steering committees for trials conducted by Biogen Idec and Novartis, and has received research support from Merck Serono, Novartis and Biogen Idec. Jose Antonio Cabrera-Gomez did not declare any competing interests.

Marc Girard received consulting fees from Teva Canada Innovation, Biogen Idec, Novartis and Genzyme Sanofi; lecture payments from Teva Canada Innovation, Novartis and EMD Serono. Dr Girard has also received a research grant from Canadian Institutes of Health Research. Marcela Fiol received honoraria from Merck-Serono and Bayer.

Maria Trojano received speaking honoraria from Biogen-Idec, Bayer-Schering, Sanofi Aventis, Merck-Serono, Teva and Novartis; has received research grants from Biogen-Idec, MerckSerono, and Novartis. 
Pierre Duquette did not declare any competing interests.

Pierre Grammond is a Novartis, Teva-neuroscience, Biogen Idec advisory board member, consultant for Merck Serono, received payments for lectures by Merck Serono, Teva-

Neuroscience and Canadian Multiple sclerosis society, and received grants for travel from Teva-Neuroscience and Novartis.

Eva Havrdova received speaker honoraria and consultant fees from Biogen Idec, Merck Serono, Novartis, Genzyme and Teva, as well as support for research activities from Biogen Idec and Merck Serono.

Dana Horakova received speaker honoraria and consulting fees from Biogen Idec, Merck Serono, Teva and Novartis, as well as support for research activities from Biogen Idec. Raed Alroughani received honoraria from Biologix, Bayer, Genpharm, Merck Sorono, GSK and Novartis, and served on advisory boards for Biologix, Genzyme, Novartis, Genpharm and Merck Sorono.

Murat Terzi received travel grants from Merck Serono, Novartis, Bayer-Schering, MerckSerono and Teva; has participated in clinical trials by Sanofi Aventis, Roche and Novartis. Raymond Hupperts received honoraria as consultant on scientific advisory boards from MerckSerono, Biogen-Idec, Genzyme-Sanofi and Teva, research funding from Merck-Serono and Biogen-Idec, and speaker honoraria from Sanofi-Genzyme.

Ricardo Fernandez-Bolanos did not declare any competing interests.

Thor Petersen received funding or speaker honoraria from Biogen Idec, Merck Serono, Novartis, Bayer Schering, Sanofi-Aventis, Roche, and Genzyme.

Freek Verheul did not declare any competing interests.

Edgardo Cristiano received honoraria as consultant on scientific advisory boards by BiogenIdec, Bayer-Schering, Merck-Serono, Genzyme and Novartis; has participated in clinical trials/other research projects by Merck-Serono, Roche and Novartis. Vincent Van Pesch has served on advisory boards for Biogen Idec and Genzyme; has received travel grants from Biogen Idec, Bayer Schering, Sanofi Aventis, Merck Serono and Novartis Pharma; has received consultancy fees from Biogen Idec, Teva and Novartis Pharma; has received research grants from Bayer Schering.

Tatjana Petkovska-Boskova did not declare any competing interests.

Fraser Moore has participated in clinical trials sponsored by EMD Serono and Novartis. Joseph Herbert did not declare any competing interests.

Maria Laura Saladino did not declare any competing interests.

Roberto Bergamaschi received speaker honoraria from Bayer Schering, Biogen, Novartis, Sanofi-Aventis, Teva; research grants from Bayer Schering, Biogen, Novartis, Sanofi-Aventis, Teva; congress and travel expense compensations from Bayer Schering, Biogen, Novartis, Sanofi-Aventis, Teva.

Norbert Vella received compensation for travel and honoraria from Novartis, Biogen Idec, Glaxo-Smith-Kline.

Mark Slee has participated in, but not received honoraria for, advisory board activity for Biogen Idec, MerckSerono, BayerSchering, Sanofi Aventis and Novartis.

Michael Barnett has served on scientific advisory boards for Biogen-Idec, Novartis and Genzyme and has received conference travel support from Biogen-Idec and Novartis. He serves on steering committees for trials conducted by Novartis. His institution has received research support from Biogen-ldec, Merck-Serono and Biogen Idec.

Maria Pia Amato received honoraria as consultant on scientific advisory boards by BiogenIdec, Bayer-Schering, Merck-Serono, Teva and Sanofi-Aventis; has received research grants by Biogen-Idec, Bayer-Schering, Merck-Serono, Teva and Novartis.

Cameron Shaw received travel assistance from Biogen Idec and Novartis..

Neil Shuey received travel grants from Novartis, Biogen Idec, and Bayer-Schering.

Carolyn Young received conference attendance support from Biogen, Novartis and Teva; speaking honoraria from Teva and Biogen; honoraria as consultant on scientific advisory boards from Genzyme and Teva; has participated in clinical trials by Cytokinetics, Teva, Biogen, Novartis, Merck Serono, Roche, Genzyme and Motor Neurone Disease Association. http://mc.manuscriptcentral.com/multiple-sclerosis 
Jeannette Lechner-Scott has accepted travel compensation from Novartis, Biogen and Merck Serono. Her institution receives the honoraria for talks and advisory board commitment and also clinic support from Bayer Health Care, Biogen Idec, CSL, Genzyme Sanofi, Merck Serono and Novartis.

Eugenio Pucci served on scientific advisory boards for Genzyme and Biogen-Idec; he has received honoraria and travel grants from Sanofi Aventis, UCB, Lundbeck, Novartis, Bayer Schering, Biogen Idec, Merck Serono, Genzyme and Teva; he has received travel grants from Associazione Marchigiana Sclerosi Multipla e altre malattie neurologiche.

Orla Gray received honoraria as consultant on scientific advisory boards for Biogen Idec, Merck Serono and Novartis; has received travel grants from Biogen Idec, Merck Serono and Novartis; has participated in clinical trials by Biogen Idec and Merck Serono.

Ludwig Kappos' Institution (University Hospital Basel) received in the last 3 years and used exclusively for research support: steering committee, advisory board and consultancy fees from Actelion, Addex, Bayer Health Care, Biogen, Biotica, Genzyme, Lilly, Merck, Mitsubishi, Novartis, Ono Pharma, Pfizer, Receptos, Sanofi-Aventis, Santhera, Siemens, Teva, UCB, Xenoport; speaker fees from Bayer Health Care, Biogen, Merck, Novartis, Sanofi-Aventis, Teva; support of educational activities from Bayer Health Care, Biogen, CSL Behring, Genzyme, Merck, Novartis, Sanofi, Teva; royalties from Neurostatus Systems GmbH; grants from Bayer Health Care, Biogen, Merck, Novartis, Roche, Swiss MS Society, the Swiss National Research Foundation, the European Union, and Roche Research Foundations. Tomas Kalincik received conference travel support and consultancy/speaker honoraria from Novartis, Biogen Idec, Sanofi Aventis, Genzyme, Teva, BioCSL and Merck Serono. Vilija Jokubaitis has received conference travel support from Novartis. Timothy Spelman received compensation for travel from Biogen Idec. Matthew Warrender-Sparkes did not declare any competing interests. 


\section{References}

1. Wingerchuk DM and Carter JL. Multiple sclerosis: current and emerging diseasemodifying therapies and treatment strategies. Mayo Clin Proc. 2014; 89: 225-40.

2. Filippini G, Del Giovane C, Vacchi L, et al. Immunomodulators and immunosuppressants for multiple sclerosis: a network meta-analysis. Cochrane Database Syst Rev. 2013; 6.

3. Tan H, Cai Q, Agarwal S, Stephenson JJ and Kamat S. Impact of adherence to disease-modifying therapies on clinical and economic outcomes among patients with multiple sclerosis. Adv Ther. 2011; 28: 51-61.

4. Kalincik T, Spelman T, Trojano M, et al. Persistence on therapy and propensity matched outcome comparison of two subcutaneous interferon beta 1a dosages for multiple sclerosis. PloS One. 2013; 8.

5. Jokubaitis VG, Spelman T, Lechner-Scott J, et al. The Australian Multiple Sclerosis (MS) immunotherapy study: a prospective, multicentre study of drug utilisation using the MSBase platform. PloS one. 2013; 8.

6. Halpern R, Agarwal S, Borton L, Oneacre K and Lopez-Bresnahan MV. Adherence and persistence among multiple sclerosis patients after one immunomodulatory therapy failure: retrospective claims analysis. Adv Ther. 2011; 28: 761-75.

7. Halpern R, Agarwal S, Dembek C, Borton L and Lopez-Bresnahan M. Comparison of adherence and persistence among multiple sclerosis patients treated with disease-modifying therapies: a retrospective administrative claims analysis. Patient Prefer Adherence. 2011; 5: 73-84.

8. Reynolds MW, Stephen R, Seaman C and Rajagopalan K. Persistence and adherence to disease modifying drugs among patients with multiple sclerosis. Curr Med Res Opin. 2010; 26: 663-74. 
9. Kleinman NL, Beren IA, Rajagopalan K and Brook RA. Medication adherence with disease modifying treatments for multiple sclerosis among US employees. Journal of Medical Economics. 2010; 13: 633-40.

10. Río J, Porcel J, Téllez N, et al. Factors related with treatment adherence to interferon b and glatiramer acetate therapy in. Mult Scler. 2005; 11: 306-9.

11. Portaccio E, Zipoli V, Siracusa G, Sorbi S and Amato MP. Long-term adherence to interferon beta therapy in relapsing-remitting multiple sclerosis. Eur Neurol. 2008; 59: 131-5. 12. Cohen JA, Barkhof F, Comi G, et al. Fingolimod versus intramuscular interferon in patient subgroups from TRANSFORMS. J Neurol. 2013; 260: 2023-32.

13. Kappos L, Radue E-W, O'Connor P, et al. A placebo-controlled trial of oral fingolimod in relapsing multiple sclerosis. N Engl J Med. 2010; 362: 387-401.

14. Khatri $B$, Barkhof $F$, Comi $G$, et al. Comparison of fingolimod with interferon beta-1a in relapsing-remitting multiple sclerosis: a randomised extension of the TRANSFORMS study. Lancet Neurol. 2011; 10: 520-9.

15. Agashivala N, Wu N, Abouzaid S, et al. Compliance to fingolimod and other disease modifying treatments in multiple sclerosis patients, a retrospective cohort study. BMC Neurol. $2013 ; 13$.

16. Oleen-Burkey M, Cyhaniuk A and Swallow E. Treatment patterns in multiple sclerosis: administrative claims analysis over 10 years. Journal of Medical Economics. 2013; 16: 397406.

17. Butzkueven H, Chapman J, Cristiano E, et al. MSBase: an international, online registry and platform for collaborative outcomes research in multiple sclerosis. Mult Scler. 2006; 12 : 769-74.

18. Prinja S, Gupta N and Verma R. Censoring in clinical trials: review of survival analysis techniques. Indian journal of community medicine : official publication of Indian Association of Preventive \& Social Medicine. 2010; 35: 217-21. 
19. Box-Steffensmeier JM and De Boef S. Repeated events survival models: the conditional frailty model. Stat Med. 2006; 25: 3518-33.

20. Meyniel C, Spelman T, Jokubaitis VG, et al. Country, Sex, EDSS Change and Therapy Choice Independently Predict Treatment Discontinuation in Multiple Sclerosis and Clinically Isolated Syndrome. PLOS ONE. 2012; 7.

21. O'Rourke KET and Hutchinson M. Stopping beta-interferon therapy in multiple sclerosis: an analysis of stopping patterns. Mult Scler. 2005; 11: 46-50.

22. Tremlett HL and Oger J. Interrupted therapy: stopping and switching of the betainterferons prescribed for MS. Neurology. 2003; 61: 551-4.

23. Bonafede MM, Johnson $\mathrm{BH}$, Wenten $\mathrm{M}$ and Watson $\mathrm{C}$. Treatment patterns in diseasemodifying therapy for patients with multiple sclerosis in the United States. Clin Ther. 2013; 35: $1501-12$

24. Rudick RA, Stuart WH, Calabresi PA, et al. Natalizumab plus interferon beta-1a for relapsing multiple sclerosis. N Engl J Med. 2006; 354: 911-23.

25. Kalincik T, Horakova D, Spelman T, et al. Switch to natalizumab versus fingolimod in active relapsing-remitting multiple sclerosis. Ann Neurol. 2015; 77: 425-35.

26. Spelman T, Kalincik T, Zhang A, et al. Switching to natalizumab versus between interferon-beta and glatiramer acetate after on-treatment relapse. Ann Clin Transl Neurol. 2015; in press.

27. Jokubaitis VG, Spelman T, Kalincik T, et al. Predictors of disability worsening in clinically isolated syndrome. Annals of Clinical and Translational Neurology. 2015: 1-10. 28. Tarrants $\mathrm{M}$, Oleen-Burkey $\mathrm{M}$, Castelli-Haley $\mathrm{J}$ and Lage MJ. The impact of comorbid depression on adherence to therapy for multiple sclerosis. Mult Scler Int. 2011; 2011. 
Table 1

\section{Baseline characteristics at first treatment initiation by DMT identity}

\begin{tabular}{|c|c|c|c|c|c|c|c|}
\hline Variable & All DMTs & IFN $\beta-1 a$ IM & IFN $\beta$-1a SC & IFN $\beta-1 b$ & GA & NAT & FTY \\
\hline Patients - n (\%) & $2640(100)$ & $812(30.8)$ & $792(30.0)$ & $520(19.7)$ & $403(15.3)$ & $68(2.6)$ & $45(1.7)$ \\
\hline \multicolumn{8}{|l|}{ Sex - n (\%) } \\
\hline Female & $1857(70.3)$ & $561(69.1)$ & $545(68.8)$ & $368(70.8)$ & $308(76.4)$ & $42(61.8)$ & $33(73.3)$ \\
\hline \multicolumn{8}{|l|}{ Location - n (\%) } \\
\hline Australia & $265(10.0)$ & $40(4.9)$ & $58(7.3)$ & $84(16.1)$ & $52(12.9)$ & $15(22.1)$ & $16(35.6)$ \\
\hline Canada & $288(10.9)$ & $75(9.2)$ & 89 (11.2) & $39(7.5)$ & 68 (16.9) & $14(20.6)$ & $3(6.7)$ \\
\hline Italy & $509(19.3)$ & $164(20.2)$ & $217(27.4)$ & $45(8.7)$ & 76 (18.9) & $6(8.8)$ & $1(2.2)$ \\
\hline Spain & $388(14.7)$ & $77(9.5)$ & $123(15.5)$ & $103(19.8)$ & $62(15.4)$ & 10 (14.7) & $13(28.9)$ \\
\hline Netherlands & $211(8.0)$ & $33(4.1)$ & 92 (11.6) & $40(7.7)$ & 44 (10.9) & $2(2.9)$ & $0(0.0)$ \\
\hline Other & 979 (37.1) & $423(52.1)$ & $213(26.9)$ & $209(40.2)$ & $101(25.1)$ & 21 (30.9) & $12(26.7)$ \\
\hline $\begin{array}{l}\text { Age at symptom } \\
\text { onset - mean (SD) }\end{array}$ & $31.7(9.6)$ & $31.1(9.5)$ & $31.2(9.6)$ & $31.8(9.3)$ & $34.1(9.9)$ & $29.0(9.7)$ & 31.5 (10.6) \\
\hline $\begin{array}{l}\text { Age at treatment } \\
\text { start - mean (SD) }\end{array}$ & $32.9(10.0)$ & $32.0(9.6)$ & $32.4(9.6)$ & $33.0(9.4)$ & $35.7(9.9)$ & $30.2(10.0)$ & $33.8(11.3)$ \\
\hline $\begin{array}{l}\text { Follow-up (years) - } \\
\text { median (IQR) }\end{array}$ & $4.8(2.4,7.1)$ & $5.4(2.9,7.2)$ & $4.6(2.3,6.9)$ & $4.8(2.6,7.0)$ & $4.2(2.0,7.0)$ & $3.0(1.8,4.5)$ & $2.6(1.7,4.9)$ \\
\hline \multicolumn{8}{|l|}{ Epoch - n (\%) } \\
\hline Pre-oral & 1884 (71.4) & $658(81.0)$ & $560(70.7)$ & $382(73.5)$ & $265(65.8)$ & 19 (27.9) & $0(0.0)$ \\
\hline Post-oral & 756 (28.6) & $154(19.0)$ & $232(29.3)$ & $138(26.5)$ & $138(34.2)$ & $49(72.1)$ & $45(100)$ \\
\hline $\begin{array}{l}\text { EDSS at treatment } \\
\text { start - median (IQR) }\end{array}$ & $2(1,2.5)$ & $1.5(1,2)$ & $2(1,2.5)$ & $2(1,2.5)$ & $2(1,2.5)$ & $2.5(1.5,4)$ & $2(1.0,2.5)$ \\
\hline $\begin{array}{l}\text { Baseline ARR - } \\
\text { median (IQR) }\end{array}$ & $0.3(0,1.5)$ & $0(0,0.7)$ & $0.9(0,1.9)$ & $0.2(0,1.4)$ & $0.6(0,1.6)$ & $1.7(0.7,2.4)$ & $0.5(0,1.4)$ \\
\hline \multicolumn{8}{|l|}{ Disease course- n (\%) } \\
\hline CIS & $678(27.6)$ & $375(46.2)$ & $99(12.5)$ & $136(26.2)$ & $61(15.1)$ & $3(4.4)$ & $4(8.9)$ \\
\hline RRMS & $1959(74.2)$ & $437(53.8)$ & $692(87.4)$ & $382(73.5)$ & 342 (84.9) & $65(95.6)$ & $41(91.1)$ \\
\hline SPMS & $3(0.1)$ & $0(0.0)$ & $1(0.1)$ & $2(0.3)$ & $0(0.0)$ & $0(0.0)$ & $0(0.0)$ \\
\hline \multicolumn{8}{|l|}{$\begin{array}{l}\text { T2 hyperintense } \\
\text { lesions - } n \text { (\% of } \\
\text { available) }\end{array}$} \\
\hline $\begin{array}{l}\text { MRI } \\
\text { available }\end{array}$ & $1810(68.8)$ & $460(56.7)$ & $575(72.6)$ & $357(68.7)$ & $289(71.7)$ & $47(69.1)$ & $36(80.0)$ \\
\hline$\geq 9$ & $672(37.1)$ & $164(35.2)$ & $200(33.7)$ & $149(41.7)$ & $104(34.7)$ & 37 (64.9) & $18(50.0)$ \\
\hline$<9$ & 1138 (62.9) & $302(64.8)$ & $394(66.3)$ & $208(58.3)$ & $196(65.3)$ & $20(35.1)$ & $18(50.0)$ \\
\hline \multicolumn{8}{|l|}{$\begin{array}{l}\text { Contrast enhancing } \\
\text { lesions - } \mathbf{n} \text { (\% of } \\
\text { available) }\end{array}$} \\
\hline MRI & $1476(55.9)$ & $380(46.8)$ & $507(64.0)$ & $288(55.4)$ & $230(57.1)$ & $44(64.7)$ & $27(60.0)$ \\
\hline
\end{tabular}


Abbreviations: n, number; DMT, Disease modifying therapy; IFN, Interferon; GA, Glatiramer Acetate; NAT, Natalizumab; FTY, Fingolimod; SD, Standard deviation; IQR, Interquartile range; EDSS, Expanded disability status scale; ARR, Annualised relapse rate; CIS, Clinically isolated syndrome; RRMS, Relapsing remitting multiple sclerosis; MRI, Magnetic resonance imaging. 
Table 2

Predictors of treatment discontinuation in the MSBasis cohort

\begin{tabular}{|c|c|c|c|c|c|c|c|}
\hline Predictor & Level & $\begin{array}{l}\text { Discontinuations / total } \\
\text { treatments } \\
\text { (\% of level) }\end{array}$ & $\begin{array}{l}\text { Discontinuation rate } \\
\text { per annum }\end{array}$ & $\begin{array}{l}\text { Univariable HR } \\
(95 \% \mathrm{CI})^{\alpha}\end{array}$ & $\mathbf{P}$ & $\begin{array}{l}\text { Multivariable HR } \\
(95 \% \mathrm{CI})^{\alpha \#}\end{array}$ & $\mathbf{P}$ \\
\hline \multirow[t]{2}{*}{ Sex } & Female & $1572 / 3095(50.8)$ & 0.21 & Reference & & Reference & \\
\hline & Male & 486/1162 (41.8) & 0.16 & $0.73(0.67,0.82)$ & $<0.001$ & $0.72(0.63,0.82)$ & $<0.001$ \\
\hline \multirow[t]{6}{*}{ Location } & Australia & $322 / 533(60.4)$ & 0.29 & Reference & & Reference & \\
\hline & Canada & $318 / 536(59.3)$ & 0.21 & $0.76(0.65,0.88)$ & $<0.001$ & $0.86(0.67,1.1)$ & 0.2 \\
\hline & Italy & $399 / 838(47.6)$ & 0.18 & $0.63(0.55,0.73)$ & $<0.001$ & $0.67(0.54,0.84)$ & $<0.001$ \\
\hline & Spain & 232/582 (39.9) & 0.14 & $0.51(0.43,0.60)$ & $<0.001$ & $0.49(0.38,0.63)$ & $<0.001$ \\
\hline & Netherlands & $165 / 315(52.4)$ & 0.25 & $0.86(0.71,1.05)$ & 0.2 & $0.85(0.62,1.18)$ & 0.3 \\
\hline & Other & $622 / 1453(42.8)$ & 0.18 & $0.64(0.56,0.74)$ & $<0.001$ & $0.68(0.55,0.85)$ & 0.001 \\
\hline \multirow[t]{6}{*}{ Treatment } & IFN $\beta$-1a SC & $567 / 1115$ (50.1) & 0.20 & Reference & - & Reference & - \\
\hline & IFN $\beta-1 a$ IM & $520 / 964(53.9)$ & 0.19 & $0.98(0.87,1.10)$ & 0.7 & $1.1(0.93,1.28)$ & 0.3 \\
\hline & IFN $\beta-1 b$ & $349 / 626(55.8)$ & 0.21 & $1.10(0.96,1.24)$ & 0.2 & $1.03(0.86,1.23)$ & 0.7 \\
\hline & GA & $374 / 718(52.1)$ & 0.23 & $1.13(0.99,1.28)$ & 0.1 & $1.04(0.87,1.25)$ & 0.6 \\
\hline & NAT & $177 / 408(43.4)$ & 0.21 & $0.93(0.78,1.10)$ & 0.4 & $1.05(0.82,1.34)$ & 0.7 \\
\hline & FTY & $71 / 426(16.7)$ & 0.11 & $0.44(0.35,0.57)$ & $<0.001$ & $0.46(0.33,0.66)$ & $<0.001$ \\
\hline \multirow[t]{2}{*}{ Epoch } & Pre-oral & $857 / 2476$ (34.6) & 0.18 & Reference & & Reference & \\
\hline & Post-oral & $1201 / 3053(39.3)$ & 0.21 & $1.22(1.11,1.35)$ & $<0.001$ & $1.64(1.44,1.86)$ & $<0.001$ \\
\hline Age at treatment start & Per 10 years & - & - & $0.88(0.84,0.93)$ & $<0.001$ & $0.80(0.74,0.85)$ & $<0.001$ \\
\hline EDSS at treatment start & 0 & $235 / 449(52.3)$ & 0.22 & Reference & - & Reference & \\
\hline
\end{tabular}




\begin{tabular}{|c|c|c|c|c|c|c|c|}
\hline & $1-3.5$ & $1328 / 2804(47.4)$ & 0.18 & $0.83(0.72,0.95)$ & 0.008 & $1.06(0.87,1.29)$ & 0.6 \\
\hline & $\geq 4$ & $231 / 416(55.5)$ & 0.26 & $1.17(0.97,1.41)$ & 0.1 & $1.50(1.14,1.97)$ & 0.004 \\
\hline & Missing* & $264 / 588(44.9)$ & 0.23 & - & - & - & - \\
\hline Change in EDSS & $\begin{array}{l}\text { Per EDSS } \\
\text { step }\end{array}$ & - & - & $1.06(1.01,1.10)$ & 0.01 & $1.04(0.99,1.10)$ & 0.08 \\
\hline $\begin{array}{l}\text { Relapses in the final } 6 \text { months of } \\
\text { observation or treatment }\end{array}$ & Per relapse & - & - & $1.86(1.74,1.98)$ & $<0.001$ & $2.27(2.07,2.50)$ & $<0.001$ \\
\hline MRI - T2 hyperintense lesion & $\geq 9$ & 498/1073 (46.4) & 0.22 & $1.10(0.99,1.23)$ & 0.08 & - & - \\
\hline & $<9$ & $911 / 1833(49.7)$ & 0.20 & Reference & & - & \\
\hline & Missing & $649 / 1351(48.0)$ & 0.18 & - & - & - & - \\
\hline MRI - Gadolinium enhancing lesion & $\geq 1$ & $281 / 628(44.7)$ & 0.20 & $1.01(0.89,1.16)$ & 0.8 & - & - \\
\hline & 0 & $887 / 1758(50.4)$ & 0.19 & Reference & & - & - \\
\hline & Missing & $890 / 1871$ (47.6) & 0.20 & - & - & - & - \\
\hline
\end{tabular}

Scaled Schoenfeld residuals test (global) for the final multivariable model: $p=0.15$.

Abbreviations: n, number; HR, Hazard Ratio; CI, Confidence Interval; IFN, Interferon; IM, Intramuscular; SC, Subcutaneous; GA, Glatiramer Acetate; NAT, Natalizumab; FTY, Fingolimod; EDSS, Expanded disability status scale; MRI, Magnetic resonance imaging.

${ }^{\alpha}$ Conditional risk set model, a variation of the Andersen-Gill proportional hazards model, adjusted for even dependence, with time to discontinuation measured from study entry.

\#Multivariable conditional risk set model was adjusted for sex, location, treatment, age at treatment start, EDSS at treatment start, change in EDSS over treatment duration, number of relapses in the 6 months leading up to treatment cessation or final visit and baseline.

*No EDSS score available at treatment start. 
Table 3

Treatment switching behaviour in the pre-oral therapy epoch

\begin{tabular}{|c|c|c|c|c|c|c|}
\hline & \multicolumn{6}{|l|}{ Initial DMT } \\
\hline & IFN $\beta$-1a IM & IFN $\beta-1 a$ SC & IFN $\beta-1 b$ & GA & NAT & Total \\
\hline Total Switches / & $194 / 733$ & $143 / 716$ & $94 / 446$ & $76 / 423$ & $12 / 158$ & $519 / 2476$ \\
\hline \multicolumn{7}{|l|}{ Total Treatments } \\
\hline \multicolumn{7}{|l|}{ Subsequent DMT } \\
\hline IFN $\beta-1 a$ IM & - & $16(11.2)$ & $16(17.0)$ & $18(23.7)$ & $1(8.3)$ & $51(9.8)$ \\
\hline IFN $\beta-1 a$ SC & $95(49.0)$ & - & $15(16.0)$ & $23(30.3)$ & $3(25.0)$ & $136(26.2)$ \\
\hline IFN $\beta-1 b$ & $29(15.0)$ & $9(6.3)$ & - & $8(10.5)$ & $1(8.3)$ & $47(9.1)$ \\
\hline GA & 42 (21.6) & $66(46.1)$ & $33(35.1)$ & - & $7(58.3)$ & $148(28.5)$ \\
\hline NAT & 28 (14.4) & $52(36.4)$ & $30(31.9)$ & 27 (35.5) & - & 137 (26.4) \\
\hline
\end{tabular}

Table refers to a subset of the study cohort, those patients who discontinued therapy and commenced a different therapy prior the introduction of oral therapies.

Abbreviations: IFN, Interferon; IM, Intramuscular; SC, Subcutaneous; GA, Glatiramer Acetate; NAT, Natalizumab 
Table 4

Treatment switching behaviour in the post-oral therapy epoch

\begin{tabular}{|c|c|c|c|c|c|c|c|}
\hline & \multicolumn{7}{|l|}{ Initial DMT } \\
\hline & IFN $\beta-1 a$ IM & IFN $\beta-1 \mathrm{a}$ SC & IFN $\beta-1 b$ & GA & NAT & FTY & Total \\
\hline Total Switches / & $172 / 593$ & $245 / 787$ & $145 / 386$ & $177 / 516$ & $103 / 347$ & $40 / 426$ & $882 / 3053$ \\
\hline \multicolumn{8}{|l|}{ Total Treatments } \\
\hline \multicolumn{8}{|l|}{ Subsequent DMT } \\
\hline IFN $\beta-1 a$ IM & - & $13(5.3)$ & $11(7.6)$ & $17(9.6)$ & $2(1.9)$ & $1(2.5)$ & $44(5.0)$ \\
\hline IFN $\beta-1 a$ SC & $69(40.1)$ & - & $7(4.8)$ & $28(15.8)$ & $7(6.8)$ & $4(10.0)$ & $115(13.0)$ \\
\hline IFN $\beta-1 b$ & $9(5.2)$ & $5(2.0)$ & - & $8(4.5)$ & $2(1.9)$ & $1(2.5)$ & $25(2.8)$ \\
\hline GA & $23(13.4)$ & $61(24.9)$ & $33(22.8)$ & - & $21(20.4)$ & $1(2.5)$ & $139(15.8)$ \\
\hline NAT & 20 (11.6) & $59(24.1)$ & $33(22.8)$ & $41(23.2)$ & - & $33(82.5)$ & $186(21.1)$ \\
\hline FTY & 51 (29.7) & $107(43.7)$ & $61(42.1)$ & $83(46.9)$ & 71 (68.9) & - & $373(42.3)$ \\
\hline
\end{tabular}

Table refers to a subset of the study cohort, those patients who discontinued therapy and commenced a different therapy after the introduction of oral therapies.

Abbreviations: DMT, Disease modifying therapy; IFN, Interferon; IM, Intramuscular; SC, Subcutaneous; GA, Glatiramer Acetate; NAT, Natalizumab; FTY, Fingolimod 
Table 5

Reasons for treatment discontinuation for all treatment commencements

\begin{tabular}{|c|c|c|c|c|c|c|c|}
\hline & IFN $\beta-1 a$ IM & IFN $\beta-1 a$ SC & IFN $\beta-1 b$ & GA & NAT & FTY & $\mathbf{P}^{\#}$ \\
\hline Commencements - $n$ & 964 & 1115 & 626 & 718 & 408 & 426 & \\
\hline Discontinuations - $\mathbf{n}$ & 520 & 567 & 349 & 374 & 177 & 71 & \\
\hline $\begin{array}{l}\text { Recorded reasons for } \\
\text { discontinuation - n (\%) }\end{array}$ & $311(59.8)$ & $284(50.1)$ & $171(49.0)$ & $189(50.5)$ & $120(67.8)$ & $53(74.6)$ & \\
\hline $\begin{array}{l}\text { Reasons recorded - n } \\
(\%)^{*}\end{array}$ & & & & & & & \\
\hline $\begin{array}{l}\text { Adverse event/lack of } \\
\text { tolerance }\end{array}$ & $69(22.2)$ & $94(33.1)$ & $53(31.0)$ & $69(36.0)$ & $18(15.0)$ & $14(26.4)$ & $<0.001^{\alpha}$ \\
\hline Lack of improvement & $94(30.2)$ & $73(25.7)$ & $34(19.9)$ & $43(22.8)$ & $13(10.8)$ & $15(28.3)$ & $0.001^{\alpha}$ \\
\hline Persistence of relapse & $18(5.8)$ & $7(2.5)$ & $10(5.8)$ & $5(2.6)$ & $0(0.0)$ & $5(9.4)$ & $0.003^{\alpha}$ \\
\hline Progression of disease & $27(8.7)$ & $16(5.6)$ & $8(4.7)$ & $14(7.4)$ & $5(4.2)$ & $1(1.9)$ & $0.3^{\alpha}$ \\
\hline MRI activity & $13(4.2)$ & $1(0.4)$ & $1(0.6)$ & $4(2.1)$ & $0(0.0)$ & $2(3.8)$ & $0.02^{\alpha}$ \\
\hline Pregnancy & $40(12.9)$ & $38(13.4)$ & $18(10.5)$ & $16(8.5)$ & $14(11.7)$ & 7 (13.2) & $0.6^{\alpha}$ \\
\hline Convenience & $26(8.4)$ & $26(9.2)$ & $22(12.9)$ & $20(10.6)$ & $12(10.0)$ & $6(11.3)$ & $0.7^{\alpha}$ \\
\hline Non-adherence & $6(1.9)$ & $8(2.8)$ & $2(1.2)$ & $5(2.6)$ & $4(3.3)$ & $2(3.8)$ & $0.7^{\alpha}$ \\
\hline Scheduled Stop & $18(5.8)$ & $21(7.4)$ & $23(13.5)$ & $13(6.9)$ & $54(45.0)$ & $1(1.9)$ & $<0.001^{\alpha}$ \\
\hline
\end{tabular}

Abbreviations: n, number; IFN, Interferon; GA, Glatiramer Acetate; NAT, Natalizumab; MRI, Magnetic resonance imaging

*Percentage of recorded reasons

${ }^{*} \mathrm{p}$-value between treatment groups

${ }^{\alpha}$ Fisher's exact test. 
1

2

3

4

5

6

7

8

9

10

11

12

13

14

15

16

17

18

19

20

21

22

23

24

25

26

27

28

29

30

31

32

33

34

35

36

37

38

39

40

41

42

43

44

45

46

47

48

49

50

51

52

53

54

55

56

57

58

59

60

Table 6

Reasons for switching to injectable therapies, fingolimod or natalizumab in the post-oral therapy epoch

\begin{tabular}{|c|c|c|c|c|}
\hline & Injectable & Natalizumab & Fingolimod & $\mathbf{P}^{\#}$ \\
\hline Switches to subsequent DMT - $\mathbf{n}$ & 323 & 186 & 373 & \\
\hline Recorded reasons for switch - n (\%) & $235(72.8)$ & $115(61.8)$ & $214(57.4)$ & \\
\hline \multicolumn{5}{|l|}{ Reasons recorded - n (\%)* } \\
\hline Adverse event/lack of tolerance & $62(26.4)$ & $8(7.0)$ & $51(23.8)$ & $<0.001^{\alpha}$ \\
\hline Lack of improvement & $50(21.3)$ & $52(45.2)$ & $67(31.3)$ & $<0.001^{\alpha}$ \\
\hline Persistence of relapse & $6(2.6)$ & $17(14.8)$ & $8(3.7)$ & $<0.001^{\alpha}$ \\
\hline Progression of disease & $11(4.7)$ & $15(13.0)$ & $9(4.2)$ & $0.007^{\alpha}$ \\
\hline MRI activity & $8(3.4)$ & $2(1.7)$ & $4(1.9)$ & $0.6^{\alpha}$ \\
\hline Pregnancy & $51(21.7)$ & $13(11.3)$ & $9(4.2)$ & $<0.001^{\alpha}$ \\
\hline Convenience & $15(6.4)$ & $3(2.6)$ & $23(10.7)$ & $0.020^{\alpha}$ \\
\hline Non-adherence & $8(3.4)$ & $2(1.7)$ & $4(1.9)$ & $0.6^{\alpha}$ \\
\hline Scheduled Stop & $24(10.2)$ & $3(2.6)$ & $39(18.2)$ & $<0.001^{\alpha}$ \\
\hline
\end{tabular}

Abbreviations: $n$, number; MRI, Magnetic resonance imaging

*Percentage of recorded reasons

" $p$-value between treatment groups

aFisher's exact test.

Pregnancy refers to mothers who recommenced a different therapy after having children. 


\title{
Figure Legends
}

\section{Figure 1}

\section{CONSORT flowchart of patient disposition.}

Abbreviations: n, number; CIS, Clinically isolated syndrome; RRMS, Relapsing remitting multiple sclerosis; SPMS, Secondary progressive multiple sclerosis; PPMS, Primary progressive multiple sclerosis.

\section{Figure 2}

\section{Kaplan-Meier estimates of treatment discontinuation.}

\author{
A: Treatment discontinuation by treatment epoch; B: Treatment \\ discontinuation by DMT identity; C: Treatment discontinuation by patient \\ sex. \\ Kaplan Meier curves were derived from treatment data not clustered by \\ patient ID, with time to discontinuation measured from treatment start.
}


- data incomplete/errors, $n=244$

- prescribed mitoxantrone, $\mathrm{n}=77$

- prescribed dimethyl fumarate or teriflunomide, $\mathrm{n}=151$

- PPMS, $n=112$

- fingolimod therapy as part of a clinical trial, $n=23$

CONSORT flowchart of patient disposition

$69 \times 52 \mathrm{~mm}(300 \times 300$ DPI $)$

MSBasis registry, Jan 2015

CIS, RRMS, SPMS

$\mathrm{n}=4111$

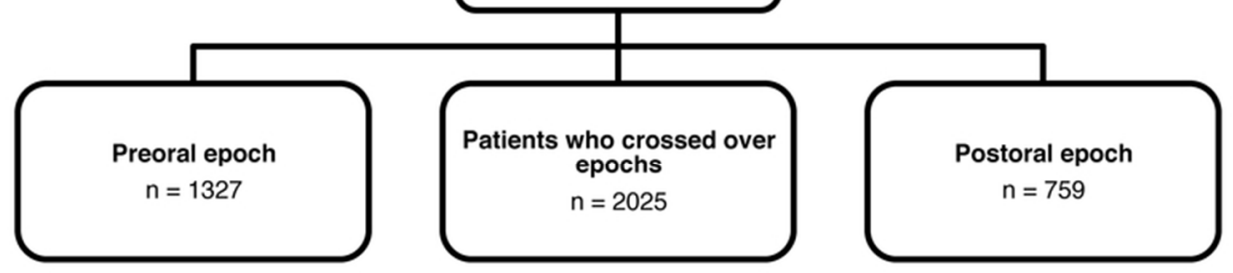



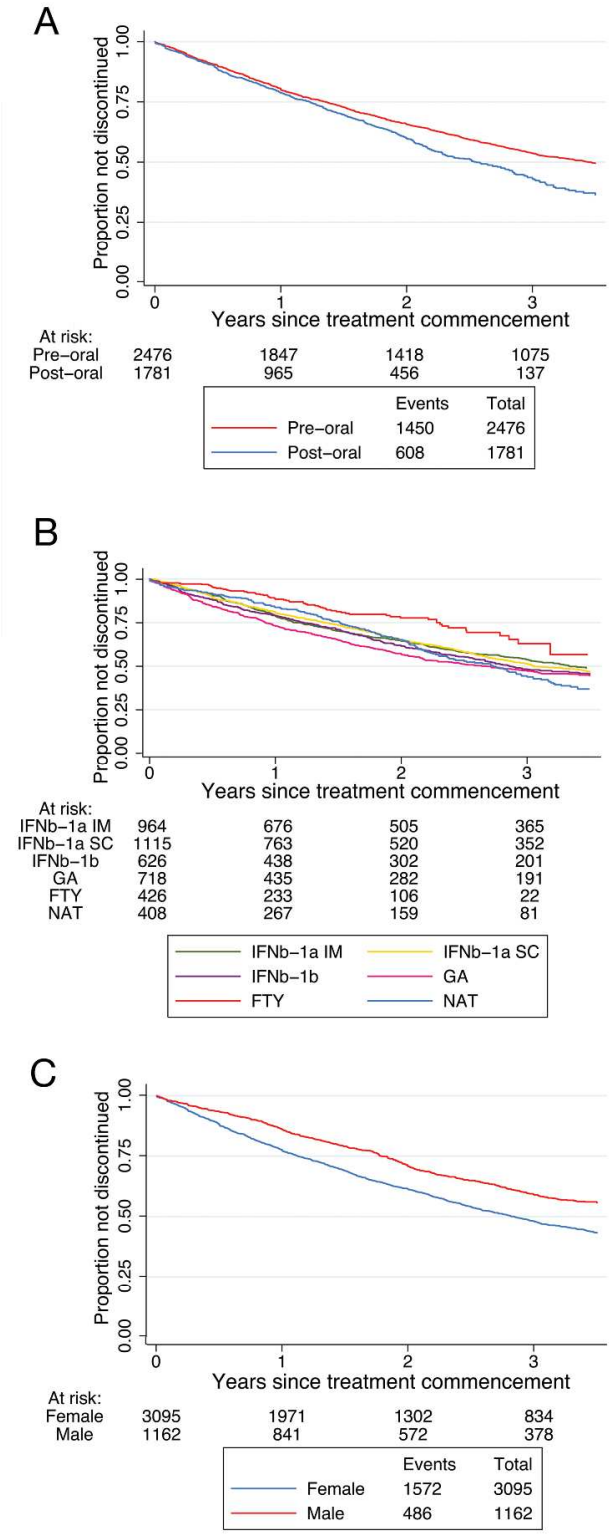

Kaplan-Meier estimates of treatment discontinuation $203 \times 458 \mathrm{~mm}(300 \times 300 \mathrm{DPI})$ 


\section{eTable 1: Number of eligible patients per centre}

\section{Centre}

FLENI

Hospital Italiano

INEBA

The Royal Melbourne Hospital

Box Hill Hospital

John Hunter Hospital

Flinders Medical Centre

BMRI

Geelong Hospital

St Vincent's Hospital

Cliniques Universitaires Saint-Luc

Neuro Rive-Sud

CHUM - Hospital Notre Dame

Hotel-Dieu de Levis

Jewish General Hospital

CIREN

General Teaching Hospital

Aarhus University Hospital

Hopital Tenon

Al-Zahra Hospital

University of Bari

University 'G. d'Annunzio'

Ospedali Riuniti di Salerno

Generale Provinciale Macerata

National Neurological Institute C. Mondino

University of Florence

Amiri Hospital

Clinic of Neurology Clinical Center

Mater Dei Hospital

University Hospital Nijmegen

Orbis Medicle Center

Groene Hart Ziekenhuis

Hospital Universitario Virgen Macarena

Hospital Universitario La Paz

Hospital Universitario Virgen de Valme

Hospital Donostia

Universitatsspital Basel

Farabi Hospital, Karadeniz Technical University

19 Mayis University, Medical Faculty

The Walton Centre for Neurology and Neurosurgery Craigavon Area Hospital

New York University Langone Medical Center

$\begin{array}{lr}\text { Country } & \begin{array}{r}\text { Eligible } \\ \text { patients }\end{array} \\ \text { Argentina } & 87 \\ \text { Argentina } & 50 \\ \text { Argentina } & 31 \\ \text { Australia } & 120 \\ \text { Australia } & 88 \\ \text { Australia } & 79 \\ \text { Australia } & 26 \\ \text { Australia } & 22 \\ \text { Australia } & 18 \\ \text { Australia } & 16 \\ \text { Belgium } & 46 \\ \text { Canada } & 187 \\ \text { Canada } & 108 \\ \text { Canada } & 95 \\ \text { Canada } & 38 \\ \text { Cuba } & 97 \\ \text { Czech Republic } & 381 \\ \text { Denmark } & 93 \\ \text { France } & 152 \\ \text { Iran } & 4 \\ \text { Italy } & 285 \\ \text { Italy } & 249 \\ \text { Italy } & 146 \\ \text { Italy } & 92 \\ \text { Italy } & 35 \\ \text { Italy } & 22 \\ \text { Kuwait } & 180 \\ \text { Macedonia } & 41 \\ \text { Malta } & 30 \\ \text { Netherlands } & 109 \\ \text { Netherlands } & 107 \\ \text { Netherlands } & 68 \\ \text { Spain } & 360 \\ \text { Spain } & 157 \\ \text { Spain } & 97 \\ \text { Spain } & 9 \\ \text { Switzerland } & 3 \\ \text { Turkey } & 204 \\ \text { Turkey } & 116 \\ \text { United Kingdom } & 13 \\ \text { United Kingdom } & 11 \\ \text { United States } & 39 \\ & \end{array}$

Cumulative

follow up (years)

165.5

150.7

84.6

635.8

418.6

291.4

109.3

107.8

50.2

117.4

231.6

936.0

667.2

639.2

189.7

519.7

1936.8

216.7

99.7

2.6

1497.4

850.0

295.0

473.6

173.7

47.8

335.3

164.7

83.0

123.5

505.7

320.5

1630.5

446.0

519.7

18.3

6.4

559.7

223.9

13.6

48.3

98.1 
STROBE Statement - checklist of items that should be included in reports of observational studies

Title: "The effect of oral immunomodulatory therapy on treatment uptake and persistence in multiple sclerosis"

\begin{tabular}{|c|c|c|c|}
\hline & $\begin{array}{l}\text { Item } \\
\text { No. }\end{array}$ & Recommendation & $\begin{array}{l}\text { Page } \\
\text { No. }\end{array}$ \\
\hline \multirow[t]{2}{*}{ Title and abstract } & \multirow[t]{2}{*}{1} & (a) Indicate the study's design with a commonly used term in the title or the abstract & 5 \\
\hline & & $\begin{array}{l}\text { (b) Provide in the abstract an informative and balanced summary of what was done and what was } \\
\text { found }\end{array}$ & 5 \\
\hline \multicolumn{4}{|l|}{ Introduction } \\
\hline Background/rationale & 2 & Explain the scientific background and rationale for the investigation being reported & 6 \\
\hline Objectives & 3 & State specific objectives, including any prespecified hypotheses & 6 \\
\hline \multicolumn{4}{|l|}{ Methods } \\
\hline Study design & 4 & Present key elements of study design early in the paper & 7 \\
\hline Setting & 5 & $\begin{array}{l}\text { Describe the setting, locations, and relevant dates, including periods of recruitment, exposure, } \\
\text { follow-up, and data collection }\end{array}$ & 7 \\
\hline \multirow[t]{2}{*}{ Participants } & \multirow[t]{2}{*}{6} & $\begin{array}{l}\text { (a) Cohort study — Give the eligibility criteria, and the sources and methods of selection of } \\
\text { participants. Describe methods of follow-up } \\
\text { Case-control study — Give the eligibility criteria, and the sources and methods of case } \\
\text { ascertainment and control selection. Give the rationale for the choice of cases and controls } \\
\text { Cross-sectional study - Give the eligibility criteria, and the sources and methods of selection of } \\
\text { participants }\end{array}$ & $7-8$ \\
\hline & & $\begin{array}{l}\text { (b) Cohort study—For matched studies, give matching criteria and number of exposed and } \\
\text { unexposed } \\
\text { Case-control study —For matched studies, give matching criteria and the number of controls per } \\
\text { case }\end{array}$ & $\mathrm{n} / \mathrm{a}$ \\
\hline Variables & 7 & $\begin{array}{l}\text { Clearly define all outcomes, exposures, predictors, potential confounders, and effect modifiers. } \\
\text { Give diagnostic criteria, if applicable }\end{array}$ & 8 \\
\hline $\begin{array}{l}\text { Data sources/ } \\
\text { measurement }\end{array}$ & $8^{*}$ & $\begin{array}{l}\text { For each variable of interest, give sources of data and details of methods of assessment } \\
\text { (measurement). Describe comparability of assessment methods if there is more than one group }\end{array}$ & $6-8$ \\
\hline Bias & 9 & Describe any efforts to address potential sources of bias & $8-9$ \\
\hline Study size & 10 & Explain how the study size was arrived at & 7 \\
\hline
\end{tabular}

Continued on next page 


\begin{tabular}{|c|c|c|c|}
\hline $\begin{array}{l}\text { Quantitative } \\
\text { variables }\end{array}$ & 11 & $\begin{array}{l}\text { Explain how quantitative variables were handled in the analyses. If applicable, describe which } \\
\text { groupings were chosen and why }\end{array}$ & $8-9$ \\
\hline \multirow{7}{*}{$\begin{array}{l}\text { Statistical } \\
\text { methods }\end{array}$} & \multirow[t]{7}{*}{12} & (a) Describe all statistical methods, including those used to control for confounding & $8-9$ \\
\hline & & (b) Describe any methods used to examine subgroups and interactions & $8-9$ \\
\hline & & (c) Explain how missing data were addressed & $8-9$ \\
\hline & & (d) Cohort study —If applicable, explain how loss to follow-up was addressed & $8-9$ \\
\hline & & Case-control study - If applicable, explain how matching of cases and controls was addressed & \\
\hline & & $\begin{array}{l}\text { Cross-sectional study - If applicable, describe analytical methods taking account of sampling } \\
\text { strategy }\end{array}$ & \\
\hline & & (e) Describe any sensitivity analyses & $\mathrm{n} / \mathrm{a}$ \\
\hline Results & & 8 & \\
\hline \multirow[t]{3}{*}{ Participants } & \multirow[t]{3}{*}{$13 *$} & $\begin{array}{l}\text { (a) Report numbers of individuals at each stage of study—eg numbers potentially eligible, examined } \\
\text { for eligibility, confirmed eligible, included in the study, completing follow-up, and analysed }\end{array}$ & Fig 1 \\
\hline & & (b) Give reasons for non-participation at each stage & Fig 1 \\
\hline & & (c) Consider use of a flow diagram & Fig 1 \\
\hline \multirow[t]{3}{*}{ Descriptive data } & \multirow[t]{3}{*}{$14 *$} & $\begin{array}{l}\text { (a) Give characteristics of study participants (eg demographic, clinical, social) and information on } \\
\text { exposures and potential confounders }\end{array}$ & $9-11$ \\
\hline & & (b) Indicate number of participants with missing data for each variable of interest & 12 \\
\hline & & (c) Cohort study-Summarise follow-up time (eg, average and total amount) & 9-10 \\
\hline \multirow[t]{3}{*}{ Outcome data } & \multirow[t]{3}{*}{$15^{*}$} & Cohort study_-Report numbers of outcome events or summary measures over time & $10-11$ \\
\hline & & Case-control study-Report numbers in each exposure category, or summary measures of exposure & \\
\hline & & Cross-sectional study-Report numbers of outcome events or summary measures & \\
\hline \multirow[t]{3}{*}{ Main results } & \multirow[t]{3}{*}{16} & $\begin{array}{l}\text { (a) Give unadjusted estimates and, if applicable, confounder-adjusted estimates and their precision } \\
\text { (eg, } 95 \% \text { confidence interval). Make clear which confounders were adjusted for and why they were } \\
\text { included }\end{array}$ & $9-12$ \\
\hline & & (b) Report category boundaries when continuous variables were categorized & $9-10$ \\
\hline & & $\begin{array}{l}\text { (c) If relevant, consider translating estimates of relative risk into absolute risk for a meaningful time } \\
\text { period }\end{array}$ & 10 \\
\hline
\end{tabular}

Continued on next page 


\begin{tabular}{lrll}
\hline Other analyses & 17 & Report other analyses done - eg analyses of subgroups and interactions, and sensitivity analyses & $11-12$ \\
\hline Discussion & & & 13 \\
\hline Key results & 18 & Summarise key results with reference to study objectives & 15 \\
\hline Limitations & 19 & $\begin{array}{l}\text { Discuss limitations of the study, taking into account sources of potential bias or imprecision. Discuss } \\
\text { both direction and magnitude of any potential bias }\end{array}$ & $13-15$ \\
\hline Interpretation & 20 & $\begin{array}{l}\text { Give a cautious overall interpretation of results considering objectives, limitations, multiplicity of } \\
\text { analyses, results from similar studies, and other relevant evidence }\end{array}$ & $15-16$ \\
\hline Generalisability & 21 & Discuss the generalisability (external validity) of the study results & 17 \\
\hline Other information & & & \\
\hline Funding & 22 & $\begin{array}{l}\text { Give the source of funding and the role of the funders for the present study and, if applicable, for the } \\
\text { original study on which the present article is based }\end{array}$ & \\
\hline
\end{tabular}

*Give information separately for cases and controls in case-control studies and, if applicable, for exposed and unexposed groups in cohort and cross-sectional studies.

Note: An Explanation and Elaboration article discusses each checklist item and gives methodological background and published examples of transparent reporting. The STROBE checklist is best used in conjunction with this article (freely available on the Web sites of PLoS Medicine at http://www.plosmedicine.org/, Annals of Internal Medicine at http://www.annals.org/, and Epidemiology at http://www.epidem.com/). Information on the STROBE Initiative is available at www.strobe-statement.org. 


\section{University Library}

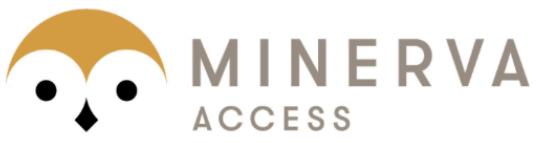

A gateway to Melbourne's research publications

Minerva Access is the Institutional Repository of The University of Melbourne

\section{Author/s:}

Warrender-Sparkes, M;Spelman, T;Izquierdo, G;Trojano, M;Lugaresi, A;Grand'Maison, F;Havrdova, E;Horakova, D;Boz, C;Oreja-Guevara, C;Alroughani, R;luliano, G;Duquette, P;Girard, M;Terzi, M;Hupperts, R;Grammond, P;Petersen, T;Fernandez-Bolanos, R;Fiol, M;Pucci, E;Lechner-Scott, J;Verheul, F;Cristiano, E;Van Pesch, V;Petkovska-Boskova, T;Moore, F;Kister, I;Bergamaschi, R;Laura Saladino, M;Slee, M;Barnett, M;Amato, MP;Shaw, C;Shuey, N;Young, C;Gray, O;Kappos, L;Butzkueven, H;Kalincik, T;Jokubaitis, V

Title:

The effect of oral immunomodulatory therapy on treatment uptake and persistence in multiple sclerosis

\section{Date:}

2016-04-01

\section{Citation:}

Warrender-Sparkes, M., Spelman, T., Izquierdo, G., Trojano, M., Lugaresi, A., Grand'Maison, F., Havrdova, E., Horakova, D., Boz, C., Oreja-Guevara, C., Alroughani, R., Iuliano, G., Duquette, P., Girard, M., Terzi, M., Hupperts, R., Grammond, P., Petersen, T., FernandezBolanos, R. ,... Jokubaitis, V. (2016). The effect of oral immunomodulatory therapy on treatment uptake and persistence in multiple sclerosis. MULTIPLE SCLEROSIS JOURNAL, 22 (4), pp.520-532. https://doi.org/10.1177/1352458515594041.

Persistent Link:

http://hdl.handle.net/11343/58400 